\title{
PROJECT MANAGEMENT INFORMATION SYSTEMS FOR CONSTRUCTION MANAGERS (CM): CURRENT CONSTITUENTS AND FUTURE EXTENSIONS
}

\author{
Youngsoo Jung ${ }^{1 *}$, Heea $\mathrm{Kim}^{1}$, and Mihee $\mathrm{Joo}^{2}$ \\ ${ }^{1}$ College of Architecture, Myongji University, Yongin, Korea \\ ${ }^{2}$ CM Division, Heerim Architects \& Planners, Seoul, Korea \\ *Corresponding author (yjung97@mju.ac.kr)
}

\begin{abstract}
This paper explores future requirements of project management information systems (PMIS) for professional construction management (CM) firms. Current constituents and effectiveness of CM-PMIS were analyzed first by surveying ten CM firms in South Korea. The composition of PMIS was quantitatively investigated by two dimensions; system configuration (e.g. in-house developed, ERP/ASP, groupware, professional software) and construction business functions (e.g. design, estimating, cost, time etc.). Information requirements from the owners and contractors are compared in order to examine the CM's role among these project participants. Current and future levels of practical utilization of CM-PMIS were also surveyed in order to evaluate the issues and needs. Findings indicate that the Korean CM firms plan to actively enhance PMIS in the areas of 'sales' and 'cost control' business functions in near future.
\end{abstract}

Keywords: Construction Manager, PMIS, ERP, Information Systems, System Configuration

\section{INTRODUCTION}

Advances in information and communications (ICT) technology have rigorously improved productivity in all industry sectors, and the role of information systems has changed further to support for even shaping organizational strategy. Thus, utilizing information systems (IS) in the construction industry has been an issue of great concern in order to achieve competitive advantages of an organization and also to enhance the effectiveness of construction projects throughout their life cycle and across different construction business functions [5].

Information systems (IS) research in the construction industry is one of the most frequently addressed areas in the academia and industry. Numerous studies have explored the IS concepts, methodologies, technologies, and solutions for specific construction tasks using the ICT. However, holistic assessment of IS in the construction is still immature due to the subjective and comprehensive nature of IS in construction [5].
Furthermore, even existing literature in holistic IS perspective in construction largely focuses on IS for the industry, owners, design firms, or contractors. There has been no systematic IS evaluation for professional construction management (CM) firms. Lack of perspectives in understanding IS in a holistic manner not only waste costly computing resources, but mismanages more expensive ones including human resources and opportunities for process improvement.

In this context, the purpose of this study is to analyze the 'current status and future direction' of CM's project management information systems (CM-PMIS). Current constituents and effectiveness of CM-PMIS were analyzed first. IS requirements from the owners and contractors are compared in order to examine the CM's role among these project participants. Future directions of CM-PMIS were also surveyed in order to evaluate the issues and needs. 


\section{FRAMEWORK FOR CM-PMIS ASSESSMENT}

Information systems assessment (ISA) issues with quantitative measures have been discussed in a limited number of literature in the construction industry. As a conceptual starting point, Betts [1] proposed a five-level framework for strategic IS from an 'industry-level' perspective. Jung et al. [6] and Stewart and Mohamed [9] developed two independent 'comprehensive and detailed IS frameworks' from the industry-level perspective by quantitatively evaluating major factors affecting effective IT utilization in the industry [2]. Jung and Joo [3] recently established another comprehensive framework from industry-level IS perception focused on building information modeling (BIM). In an attempt to systematically evaluate the benefits from IS on a 'company-level' perspective, Jung and Gibson [5] developed a comprehensive and quantitative assessment methodology that primarily identifies the most promising IS areas.

While the industry-level perspective stresses the generally applicable variables of ISA (e.g. life cycle, standards, data property), company-level perspective articulates more organization-specific issues (e.g. strategy, processes, systems). Among these variables, construction business function (e.g. design, estimating, cost control) is commonly utilized both for industry- and company-level perspectives.

Unlike project management information systems (PMIS) of the owners, architects/engineers, and contractors, CMPMIS should be flexible enough in order to meet the varying CM's responsibility as the scope of CM contract is very different from project to project. This fact forces CM firms to utilize more commercial off-the-shelf applications than in-house developed systems in terms of IS configurations.

Based on these distinct characteristics of CM's role and responsibilities, this study selected the 'construction business function' and 'systems configuration' as two fundamental dimensions for CM-PMIS assessment.

\section{VARIABLES FOR CM-PMIS ASSESSMENT}

Construction business function can be defined in many different forms. A good reference is nine areas introduced in the body of knowledge (BOK) defined by Project Management Institute (PMI) [8]. The nine areas include "integration, scope, time, cost, quality, human resource, communications, risk, and procurement" management. Jung and Gibson [5] defined fourteen business functions for the construction industry; planning, sales, design, estimating, scheduling, materials management, contracting, cost control, quality management, safety management, human resource management, accounting/financing, general administration, and R\&D.

'Construction business function' variable in this paper adapts the fourteen functions defined by Jung \& Gibson [5] The fourteen functions have been used in a series of ISA efforts in the construction industry by the author. Therefore this variable can serve as a common denominator for comparing IS requirements for owners, CMs, and contractors.

Systems configuration as the second dimension consists of two aspects. One is the method of systems development and acquisition. This paper classified information systems into four groups; Systems 1) developed in-house (proprietary), 2) purchased as enterprise resource planning (ERP) or application service provider (ASP) packages, 3) utilized as groupware systems, or 4) acquired as specialty software such as CAD, CPM, and professional systems.

Another aspect of 'systems configuration' variable is the data form of each construction business function. Structured data represent that systems contains records with well-organized attribute (e.g. relational database for cost control function). Unstructured data may encompass various types of information (e.g. documents, spread sheets, images, pictures, and so on). The degree of structured data in an application is a measure to characterize the IS for each construction business function. 
Table 1. CM-PMIS Configuration (Survey Result of 10 CM Firms)

\begin{tabular}{|c|}
\hline \\
Biz Function \\
(Jung \& Gibson 1999) \\
\\
\hline Planning \\
\hline Sales \\
\hline Design \\
\hline Estimating \\
\hline Scheduling \\
\hline Materials Mgmt \\
\hline Contracting \\
\hline Cost Control \\
\hline Quality Mgmt \\
\hline Safety Mgmt \\
\hline HR Mgmt \\
\hline Accounting \\
\hline General Admin \\
\hline R\&D \\
\hline Total \\
\hline
\end{tabular}

\begin{tabular}{|c|c|c|c|c|}
\hline \multicolumn{5}{|c|}{ IS Configuration } \\
\hline $\begin{array}{l}\frac{2}{\pi} \\
\frac{\tilde{N}}{\frac{\pi}{2}} \\
\frac{0}{0} \\
\frac{2}{2}\end{array}$ & 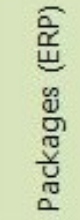 & $\begin{array}{l}\frac{\Perp}{\pi} \\
\frac{\pi}{3} \\
\frac{0}{3} \\
0 \\
0 \\
0\end{array}$ & $\begin{array}{l}\frac{⿱}{\frac{\pi}{\pi}} \\
\frac{\pi}{d} \\
\frac{0}{n}\end{array}$ & $\begin{array}{l}\bar{\pi} \\
\stackrel{0}{\circ} \\
\stackrel{\circ}{2}\end{array}$ \\
\hline 1.9 & 0.2 & 0.5 & 0.9 & 3.5 \\
\hline 3.4 & 0.5 & 0.9 & 1.1 & 5.9 \\
\hline 2.6 & 1.1 & 1.2 & 9.0 & 13.9 \\
\hline 1.5 & 0.7 & 0.4 & 1.3 & 3.9 \\
\hline 0.3 & 3.6 & 0.3 & 3.5 & 7.7 \\
\hline 1.5 & 1.4 & 0.2 & 1.0 & 4.2 \\
\hline 4.3 & 1.2 & 0.4 & 0.7 & 6.6 \\
\hline 3.0 & 2.3 & 0.4 & 1.4 & 7.1 \\
\hline 2.1 & 1.7 & 0.5 & 1.3 & 5.6 \\
\hline 1.6 & 1.2 & 0.5 & 1.0 & 4.4 \\
\hline 7.7 & 2.8 & 2.6 & 1.5 & 14.6 \\
\hline 4.5 & 2.7 & 2.9 & 1.1 & 11.2 \\
\hline 3.7 & 0.8 & 3.1 & 0.8 & 8.4 \\
\hline 1.4 & 0.2 & 0.5 & 1.1 & 3.3 \\
\hline 39.7 & 20.4 & 14.5 & 25.6 & 100 \\
\hline
\end{tabular}

\begin{tabular}{|c|c|}
\hline \multicolumn{2}{|c|}{ Data } \\
\hline 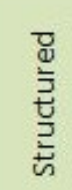 & 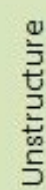 \\
\hline 1.1 & 2.5 \\
\hline 1.4 & 4.5 \\
\hline 5.9 & 7.8 \\
\hline 1.8 & 2.1 \\
\hline 2.7 & 5.0 \\
\hline 2.4 & 1.8 \\
\hline 4.0 & 2.6 \\
\hline 3.6 & 3.6 \\
\hline 2.9 & 2.7 \\
\hline 1.9 & 2.4 \\
\hline 10.9 & 3.6 \\
\hline 7.6 & 3.6 \\
\hline 5.0 & 3.5 \\
\hline 1.1 & 2.1 \\
\hline 52 & 48 \\
\hline
\end{tabular}

\section{SURVEY QUESTIONNAIRE OUTLINES}

A survey questionnaire was prepared based on the CMPMIS assessment framework and variables. The questionnaire was sent out to top tier CM firms (CM for fee) in South Korea in October 2010. Ten companies responded, and average annual revenue of the companies is 80 million dollars. Table 1 shows average score from ten respondents.

Respondents were asked to fill out the cells by construction business functions first. For an example, a respondent gave weightings of IS configuration for 'cost control' row (similar form as Table 1) as being $40 \%, 30 \%, 10 \%, 20 \%$ for proprietary, packages, groupware, and specialty, respectively. After repeating to fill out weightings for all fourteen construction business functions, the respondent then gave weighting of 'cost control' among fourteen business functions in terms of the IS size (the column of 'total' in Table 1). If the weighting of 'cost control' was 7\%, the weight of proprietary, packages, groupware, and specialty systems in 'cost control' row will get 2.8\%, 2.1\%, $0.7 \%$, and $1.4 \%$, respectively. This value is calculated from the weightings of each package, groupware, and specialty in 'cost control' row multiplied by the weighting of 'cost control' function. Note that Table 1 illustrates the simplified final scores after converting and averaging ten responses. The questionnaire was designed in easier format to answer with explanations and examples.

In addition to the systems configuration, the questionnaire also surveyed respondent's level of IS utilization for each construction business function. Future plans for IS enhancement, promising areas for data sharing between owners and contractors were also asked in the questionnaire. The questionnaire was designed simply. However, it comprehends a variety of IS issues for assessing and planning for the future. 


\section{CM-PMIS: SYSTEMS CONFIGURATION}

As depicted in Table 1, it is found that 39.7\% of CM-PMIS is in-house developed (proprietary) systems. Package (ERP/ASP), groupware, and specialty software count for 20.4\%, 14.5\%, and 25.6\%, respectively. Top-tier Korean general contractors usually have much higher proportion for proprietary systems. Therefore, it is inferred from the survey result that CM firms need higher flexibility in PMIS. This fact was also support by Jung and Gibson [4] in their study comparing PMIS under different project delivery methods.

Among these proprietary systems (39.7\%), human resource (HR) management (7.7\%), accounting (4.5\%), contracting (4.3\%), general administration (3.7\%) and sales (3.4\%) counts for $23.6 \%$. Namely, most of the proprietary systems are in less project-oriented (or less engineering-oriented) areas. On the other hand, specialty software (25.6\%) is mainly used for design (9.0\%) and scheduling (3.5\%), which are more engineering-oriented.

For the nature of data structure in CM-PMIS, only half of entire data (52\%) is 'structured'. Except HR management (10.9\%) and accounting (7.6\%) as for less engineeringoriented, design (5.9\%), contracting (4.0\%), and cost control (3.6\%) has relatively higher proportion for structured data. Nevertheless, interestingly enough, the unstructured proportions for design (7.8\%) and cost control (3.6) are equal or even greater than structured. This finding also clearly shows the distinct characteristics of CM firms' PMIS. The higher proportion of groupware and specialty software implies the unstructured nature of CM's dataset. However, low numbers of structured data proportion, especially engineering functions including cost control, reveals that $\mathrm{CM}$ firms need to improve not only reporting mechanism to the owners but also managing methods for their projects.

From the construction business function dimension (rows in Table 1), major areas of CM-PMIS include HR management (14.6\%), design (13.9\%) accounting (11.2\%), general administration (8.4\%), scheduling (7.7\%), cost control (7.1) in the order of system size. Within engineering emphasis, design (13.9\%), scheduling (7.7\%), and cost control (7.1) are found as being the major PMIS functions for CM firms. Note that 'Design' function includes design management in its definition.

The average IS expenditure to annual revenue was $0.6 \%$, and average number of full-time IS staff was 4.4. It is recommended that IS investment in terms of expenditure and professional staff should be increased in order to enhance the CM-PMIS.

\section{CM-PMIS: CURRENT \& FUTURE DIRECTION}

The survey questionnaires asked respondents to evaluate current level of PMIS utilization (in terms of frequency and satisfaction) for each construction business function. Future directions for PMIS enhancement were also evaluated. Each construction business functions were scored by using a scale of one to five in the questionnaire. In order to reduce the individual subjectivity of the scale, scores are normalized where the score of 100 means exact average and median. The total of each column in Table 2 thus indicate 1,400 that is total score of 14 business functions.

Survey results illustrate that design (120.1) and cost control (108.8) are the two most utilized systems at present. HR management and Accounting are not included in this discussion in order to focus on CM functions. CM firms desire to enhance IS in the areas of sales (122.6), cost control (115.6), and contracting (115.2). Even though the relative score is low, material management is an area for future improvement (gap is significant).

In summary, CM-PMIS in South Korea has focused on design, scheduling, and cost control. Future extensions will concentrate on sales, contracting, and materials management. This trend may be affected by overall construction business environment. The owners' and contractors' IS requirements are compared with CM-PMIS to monitor this industry trend in the next chapter. 
Table 2. Information Requirement between Owner, CM, Contractor

\begin{tabular}{|c|c|c|c|c|c|c|c|c|c|}
\hline \multirow{2}{*}{$\begin{array}{c}\text { Biz Function } \\
\text { (Jung \& Gibson 1999) }\end{array}$} & \multicolumn{3}{|c|}{$\begin{array}{c}\text { Owner } \\
\text { (Jung et al. 2004a) }\end{array}$} & \multicolumn{3}{c|}{$\begin{array}{c}\text { CM } \\
\text { (This Study) }\end{array}$} & \multicolumn{3}{c|}{$\begin{array}{c}\text { Contractor } \\
\text { (Jung et al. 2004b) }\end{array}$} \\
\cline { 2 - 12 } & As-Is & To-Be & Gap & As-Is & To-Be & Gap & As-Is & To-Be & Gap \\
\hline Planning & 97.4 & 124.6 & 27.2 & 92.9 & 94.6 & 1.7 & 89.3 & 92.1 & 2.8 \\
\hline Sales & 86.0 & 92.9 & 6.9 & 97.1 & 122.6 & 25.5 & 105.4 & 100.3 & \\
\hline Design & 99.0 & 109.5 & 10.5 & 120.1 & 105.1 & & 76.2 & 88.7 & 12.5 \\
\hline Estimating & 103.8 & 114.6 & 10.8 & 101.3 & 94.6 & & 98.3 & 108.6 & 10.3 \\
\hline Scheduling & 108.1 & 104.2 & & 101.3 & 108.9 & 7.6 & 90.2 & 107.2 & 17.0 \\
\hline Materials Mgmt & 105.0 & 84.1 & & 75.1 & 87.5 & 12.5 & 110.8 & 104.5 & \\
\hline Contracting & 114.6 & 106.1 & & 90.1 & 115.2 & 25.1 & 104.5 & 106.5 & 2.0 \\
\hline Cost Control & 98.0 & 99.5 & 1.5 & 108.8 & 115.6 & 6.7 & 112.6 & 108.6 & \\
\hline Quality Mgmt & 98.9 & 97.2 & & 101.3 & 94.6 & & 90.2 & 99.7 & 9.4 \\
\hline Safety Mgmt & 97.3 & 87.8 & & 86.3 & 91.1 & 4.7 & 87.5 & 90.7 & 3.2 \\
\hline HR Mgmt & 88.1 & 83.8 & & 121.6 & 96.5 & & 120.6 & 104.5 & \\
\hline Accounting/Financing & 101.5 & 99.5 & & 120.1 & 115.6 & & 136.7 & 112.7 & \\
\hline General Admin & 92.3 & 83.0 & & 91.2 & 77.8 & & 101.8 & 92.8 & \\
\hline R\&D & 110.1 & 113.1 & 3.0 & 92.9 & 80.5 & & 75.9 & 83.2 & 7.2 \\
\hline Total & 1400 & 1400 & & 1400 & 1400 & & 1400 & 1400 & \\
\hline
\end{tabular}

\section{PMIS FOR OWNER-CM-CONTRACTOR}

Under any circumstances, a CM serves as an information bridge between the owner and contractor. In order to examine this inter-relationship between CM-PMIS and owner (or contractor) IS requirements, two relevant studies are re-organized in Table 2.

Jung et al. [7] analyzed the current (As-Is) and future (ToBe) capability required by 11 public owner organizations. Even though this survey quantified the project management capability instead of PMIS, it provides a good reference to be compared with CM-PMIS. Results of the study [7] indicate that the Korean public owners had strength on contracting (114.6), scheduling (108.1), and material management (105.0). However, they want to enhance the capabilities in planning (124.6), estimating (114.6), and design (109.5) in near future. This figure support the fact that owner are getting smarter in facility management.

Another research by Jung et al. [6] investigated the degree of informatization for Korean general contractors. A systematic assessment methodology was proposed, and various quantitative analyses were performed. Part of results from Jung et al. [6] was re-organized in Table 2. It shows that general contractors have focused on cost control (112.6) and materials management (110.8). Their future plan is to augment the estimating (108.6) and scheduling (107.2). Under the globalized competition, Korean general contractors strive to achieve competitive advantages in technical capabilities. The survey result well depicts these trends.

CM-PMIS in Table 2 is located in the middle between the owner and the contractor. The three surveys put in together represent their inter-relationships. The owners are getting more interested in planning, design and estimating of construction projects. Therefore, some owners now require well-organized project data for their future use. CM firms stress capabilities in design, scheduling, and cost control, and they plan to expand further into more engineering areas. Korean general contractors are also moving toward the same direction. 


\section{CONCLUSIONS}

This paper proposed an information systems assessment methodology for CM firms with two major dimensions; 'construction business function' and 'systems configuration'. Measures for effectiveness of information systems are also added in order to assess the future direction.

A case study introduced in this paper validates that the proposed methodology is simple enough to utilize and, at the same time, comprehensive enough to address full range of planning issues for PMIS.

Findings from the case study indicate that the PMIS for CM firms has flexibility due to the distinct characteristics of CM. It is also found that the Korean owners, CMs, and contractors have a common trend in developing PMIS.

\section{AKNOWLEDGEMENTS}

This study was supported by Korean Ministry of Education, Science, and Technology (MEST) under Grant No. 20090074881. The support to research project titled “Automated Progress Measurement and Management for Construction Projects” is gratefully acknowledged.

\section{REFERENCES}

[1] Betts, M. “Technology Planning Frameworks to Guide National IT Policy in Construction”, Automation in Construction, 3(4), pp. 251-266, 1995.

[2] Jung, Y. "Automated Front-End Planning for Cost and Schedule: Variables for Theory and Implementation", Proceedings of the 2008 Architectural Engineering National Conference, ASCE, Denver, USA, doi: 10.1061/41002(328)43, 2008.

[3] Jung, Y. and Joo, M. "Building Information Modeling (BIM) Framework for Practical Implementation", Automation in Construction, 20(2). pp. 126-133, 2011.
[4] Jung, Y. and Gibson, G.E. "Variation in CIC Driving Factors based upon Types of Construction Contracts." Proceedings of the Fifth International Conference on Automation Technology, Taipei, Taiwan, pp.199-, D5-1, 1998.

[5] Jung, Y. and Gibson, G.E. "Planning for Computer Integrated Construction", Journal of Computing in Civil Engineering, Vol. 13(4), pp. 217-225. 1999.

[6] Jung, Y., Chin, S., and Kim, K. "Informatization Index for the Construction Industry”, Journal of Computing in Civil Engineering, 18(3), pp. 267-276, 2004b.

[7] Jung, Y., Woo, S., Park, J., Kang, S., Lee, Y., Lee, B.N. "Evaluation of the Owners' CM Functions", Korean Journal of Construction Engineering and Management, 5(3), pp. 128-136, 2004a.

[8] PMI. A Guide to the Project Management Body of Knowledge (PMBOK). 4th Ed., .Project Management Institute (PMI). Newtown Square. PA., U.S.A. , 2008.

[9] Stewart, R. A. and Mohamed, S. "Evaluating Webbased Project Information Management in Construction: capturing the long-term value creation process", Automation in Construction, 13(4), pp. 469473, 2004. 